\title{
Non-Clinical Gestation Trial Phase
}

National Cancer Institute

\section{Source}

National Cancer Institute. Non-Clinical Gestation Trial Phase. NCI Thesaurus. Code C124602.

The period of time in a non-clinical study beginning with evidence of mating observation until cesarean section or delivery. 